\title{
STOMACH BEZOARIS, CAUSES OF DEVELOPMENT, DIAGNOSIS AND METHODS OF TREATMENT
}

10.36740/WLek202101125

\author{
Oleh 0. Vorovskiy, Yuliia Yu. Shushkovska, Oksana I. Afanasiuk \\ NATIONAL PIROGOV MEMORIAL MEDICAL UNIVERSITY, VINNYTSIA, UKRAINE
}

\begin{abstract}
The aim: Is to determine the tactics and methods of treatment of bezoars of the gastrointestinal tract.

Materials and methods: From 2001 to 2019, 17 patients were diagnosed with "bezoar".

Results: Due to the "weariness" of the clinic, the diagnosis was made in the first 3 days only for $3(17,6 \%)$ patients. On the basis of the obtained average $\mathrm{pH}$ values for 4 (23,5\%) patients established moderate hypoacid, for 4 (23,5\%) - pronounced hypoacid, for 6 (35,3\%) - anacid. For 5 (29,4\%) patients, the bezoars were withdrawn on the first attempt, while the other 5 (29,4\%) were "lumped". In the course of fibrogastroscopic examination, all patients were diagnosed with impaired motor-evacuation function of the stomach: gastroesophageal and duodenogastric refluxes, presence of passive discharge of the contents of the stomach into the esophagus.

Conclusions: Therefore, the preconditions for the development of bezoars may be: hypo- and anacid, impaired motor-evacuation function of the stomach, chronic gastric ulcer, cognitive impairment. Endoscopic method should be preferred in the treatment, on condition of its failure - laparoscopic gastrotomy with bezoar extraction.
\end{abstract}

KEY WORDS: gastric bezoar, intragastric pH-metry, endoscopy

Wiad Lek. 2021;74(1):128-131

\section{INTRODUCTION}

Bezoars are foreign bodies formed as a result of swallowing of substances that are not digested in the stomach and accumulate in the lumen of the gastrointestinal tract (GIT). The most common location for bezoar is the stomach. There are several types of bezoaris. Phytobezoar is the most common type of bezoar, which occurs in about $75 \%$ of all types of bezoar, and is formed as a result of the use of a large number of bezorogenic products of plant origin, including grapes, persimmon (diospirobesoar), dates, figs, dogwood, cherries and sweet cherries, corn, pineapple [1, 2, 3]. Such types are also distinguished: lactobesoir - accumulation of lactose and casein (is common for children) [4]; pharmacobezoir - caused by the use of tableted drugs [5], which include: aluminum hydrochloride gel, intestinal aspirin, sucralfate, cholestyramine, nifedipine [6, 7]; Sebobezoar - is formed by refractory animal fats in the form of fatty conglomerates, shellacobezoar (or pixo- or desmobezoar) - resins and bitumen $[1,8]$; trichobezoar - the aggregation of hair between the folds of the stomach $[9,10]$, which occurs more often in women up to 30 years [11], is associated with mental illness and bad habits: trichotomomania (tearing hair) and trichophagia (swallowing hair), it can "tail" spread to the intestine (Rapunzel syndrome) [12]; polybezoar - mixed genesis $[1,8]$.

It is believed that risk factors for the development of bezoar are a decrease in gastric motility, which may be due to: gastroparesis, postoperative adhesive disease, cystic fibrosis, intrahepatic cholestasis, diabetes mellitus, hypothyroidism and renal failure. Patients with impaired chewing function, psychiatric illnesses also fall into the risk category of bezoar formation [5].

The publications indicate that this pathology on the early stages of the disease has a low symptomatic clinical picture and depends on the location of the bezoar, its structure and size, duration of the disease. This category of patients is characterized by dyspeptic complaints, weight loss, which appear later. As a rule, bezoars are diagnosed when they cause pylorus obstruction, intestinal obstruction, ulcerative ulcers of the mucous membrane, and subsequently - GI bleeding $[13,14,15]$. Fibrogastroduadenoscopy (FGDS), radiological imaging techniques such as ultrasound (ultrasound) and computed tomography (CT) of abdominal cavity (OCP), direct abdominal radiography, X-ray diffraction are used for the diagnosis of bezoars. The radiographs of the radiographs appear as spotty or homogeneous floating masses [16, 17, 18].

A retrospective multicenter study showed that more than a third of patients were not diagnosed with gastric bezoars during primary endoscopic examination [19], which required additional diagnostic imaging techniques to help establish the diagnosis. Thus, on CT, phytobezoaris appear to be clearly defined, rounded or ovate masses with heterogeneous density [20].

In the treatment of phytobezoars the following methods are offered: chemical dissolution of bezoar (L-cysteine and metoclopramide together with cellulose, papain with cellulose, pineapple juice, saline, soda, hydrochloric acid, 


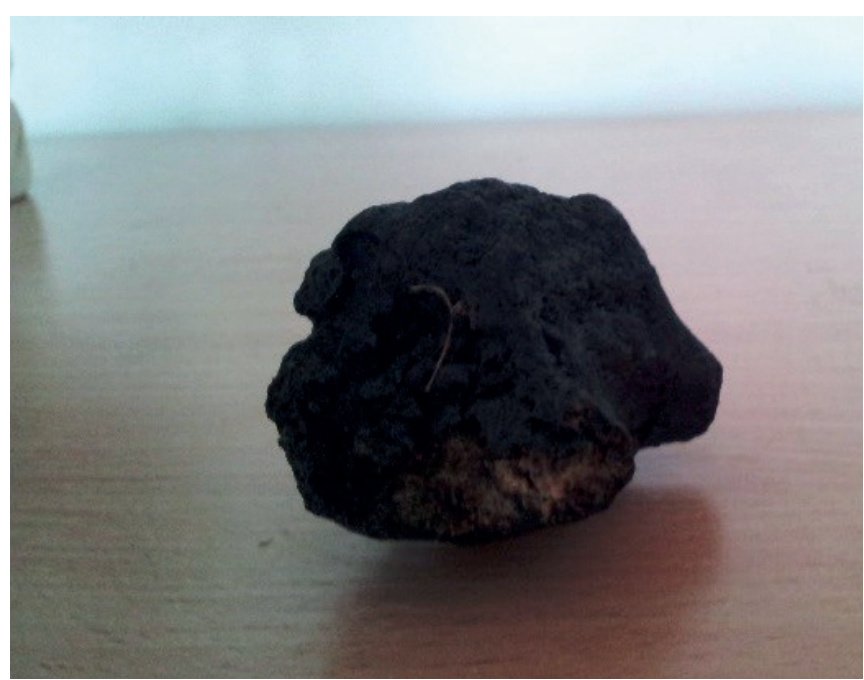

Fig. 1. Phytobezoar stomach

pancreatin, 1-2\% zinc chloride, and even zinc chloride, and cola) $[14,21]$, removal with endoscopic devices, laparotomy [22, 23], laparoscopic treatment approach is preferred over open surgery [24].

Thus, according to various authors, there is no single concept in the diagnosis and methods of treatment, the criteria for the use of surgical treatment are not fulfilled.

\section{THE AIM}

The aim is to determine the tactics and methods of treatment of bezoars of the gastrointestinal tract.

\section{MATERIALS AND METHODS}

From 2001 to 2019, 17 patients were diagnosed with "bezoar". The age of patients ranged from 25 to 82 years, the average was 58,0 $\pm 2,5$ years. By gender, there were 13 men $(76,5 \%)$, women - $4(23,5 \%)$. For all patients, this diagnosis was established during treatment in hospitals of different profiles. $12(70,6 \%)$ patients were over 60 years old with comorbid pathology. In the hospitalization period, 10 (58,8 \%) patients had cardiac pathology first, $5(29,4 \%)$ had neurological pathology, and only $2(11,8 \%)$ had a gastrointestinal chronic obstruction clinic. were hospitalized in the surgical ward.

For $15(88,2 \%)$ patients a short-term intragastric $\mathrm{pH}$-metry was used to study the acid-forming and acid-neutralizing functions of the stomach under basal conditions and after stimulation with pentagastrin. The average $\mathrm{pH}$ levels in different departments of the stomach were measured using an AG-1rN-M acidogastrograph developed at National Pirogov Memorial Medical University, Vinnytsya (State Registration Certificate No. 6226/2007 dated March 16, 2007).

In most cases, the diagnosis was made endoscopically, for $3(17,6 \%)$ patients with ultrasound ultrasound, for $2(11,8 \%)$ - with CT. In $10(58,8 \%)$ cases, the bezoaras were removed endoscopically, in 7 (41,2\%) operatively, 5 of them $(29,4 \%)$ - laparoscopically.

\section{RESULTS}

The diagnosis of "bezoar" was established for all patients within 10 inpatient days. In the first 3 days, this pathology was diagnosed only for $3(17,6 \%)$ patients who were diagnosed with "stenosis of the exit from the stomach of oncological genesis", which was caused by the "weariness" of the clinical picture. In the FGDS study, in one case, sebobezoar was accepted as a malignant tumor, the diagnosis was made during the second study, which was managed to eliminate with the help of laparoscopic gastrostomy.

The patients' main complaints were: unreasonable vomiting, which was usually associated with overeating; early saturation; feeling of stomach overflow after breakfast; burping with "rotten eggs"; weight loss with preserved appetite. There was a diagnosis of "Stenosis of the stomach cancer oncology genesis". In the group of patients with cardiac pathology, complaints came first: breast and epigastric pain, shortness of breath, and dyspeptic complaints - in the second place. For patients with a neurological clinic, the dyspeptic symptoms were hidden by the root syndrome of osteochondrosis of the lumbar spine. Thus, in 15 (88,2\%) cases, this pathology had "hidden" or asymptomatic clinical picture.

In the study of acid-forming and acid-neutralizing functions of the stomach by intragastric $\mathrm{pH}$-metry, moderate hyperacid was diagnosed from $15(88,2 \%)$ for 1 patient (5,9 \%), 4 (23,5\%) - moderate hypoacid, for $4(23,5 \%)$ - pronounced hypoacid, for $6(35,3 \%)$ - anacid. During the FGDS in all patients were found signs of impaired motor-evacuation function of the stomach, namely, gastroesophageal and duodenogastric refluxes - for $14(82,4 \%)$ people, the presence of passive discharge of the contents of the stomach into the esophagus - for 4 (23,5\% ).

In the treatment of this pathology, preference was given to endoscopic methods. For $5(29,4 \%)$ patients, bezoars were withdrawn on the first attempt, the other $5(29,4 \%)$ this manipulation was performed several times with the method of "lumping", small residues were moved independently on the digestive tract. For seven $(41,2 \%)$ patients, where the bezoars had a dense structure and considerable size, an operative method of treatment was applied, which included gastrostomy and extraction of the bezoar from the lumen of the stomach. $5(29,4 \%)$ patients had this surgery laparoscopically, $2(11,8 \%)$ with the clinic of stenosis of the exit from the stomach on the background of cognitive impairment were forced to perform gastrostomy laparotomy access. According to the morphological structure of bezoars, they were divided as follows: phytobezoaris - $9(52,9 \%)$, where the fruit bones were the basis (Fig. 1); trichobezoaris - 6 (35,3\%), consisting of hair and pieces of matter; sebobezoaris - $2(11,8 \%)$, the basis of which was the so-called "combined fat" of canned food.

\section{DISCUSSION}

During the study it was found that this pathology mainly affects older people. Thus, out of $17(100,0 \%)$ for $9(52,9 \%)$ patients, this pathology was more than 75 years old, 
characterized by significant comorbidity of the disease, including cognitive impairment, which contributes to the inadequacy of complaints, "hidden" of the clinic and its low symptomatic the course. This statement confirms the morphological composition of bezoaris, in which 9 (52,9\%) had phytobezoaris with the basis of the bones of berries and in 6 cases $(35,3 \%)$ - trichobezoaris, which were based on hair and pieces of matter.

Our study of acid-forming function of the stomach makes it possible to state that patients with impaired motor-evacuation functions of the gastrointestinal tract, with hypo- and anacid of the stomach, are at risk of developing this pathology.

By far, FGDS has the highest diagnostic value. However, diagnostic alertness should be exercised when conducting other studies, such as ultrasound ultrasound and CT, differential diagnosis with oncopathology, peptic ulcer, etc.

Conservative treatment of these formations is considered unpromising, since the use of various chemical compounds that, according to other authors, dissolve the formation data, can adversely affect the gastric mucosa and other organs and systems of the body.

In the treatment of bezoaris, it is desirable to give preference to endoscopic extraction, which can be performed on the early stages of the disease, when the formation is small, "loose" in structure, amenable to fragmentation ("lumping" method). In the case of involuntary surgery, for the elderly a less invasive method is recommended laparoscopic gastrotomy with bezoar extraction, which contributes to the early activation of patients and the reduction of postoperative complications in the older age category.

\section{CONCLUSIONS}

Therefore, the preconditions for the development of bezoars may be: hypo- and anacid, impaired motor-evacuation function of the stomach, chronic gastric ulcer, cognitive impairment. In the treatment endoscopic method should be preferred, if it is impossible to carry out - laparoscopic gastrotomy with bezoar extraction.

\section{REFERENCES}

1. Gizha L.Y., Tsyupka B.V., Gizha B.I. Bezoar zheludka i kishechnika u devochki s oligofreniyey. [Bezoar of the stomach and intestines in a girl with oligophrenia]. Sovremennaya pediatriya. 2016;1 (72):146-147. (in Russian). Available from: http://sp.med-expert.com.ua/article/view/ SP.2016.73.146.

2. Espinoza R.G. Gastrointestinal bezoars. Rev Med Chil. 2016;144(8):10731077. doi: $10.4067 / S 0034-98872016000800016$.

3. Kajihara Y. Gastric bezoar (phytobezoar). Postgrad Med J. 2019;95(1126):455. doi: 10.1136/postgradmedj-2019-136746.

4. Chahine E., El Khoury L., Baghdady R., Chouillard E. Recurrent gastric metal bezoar: a rare cause of gastric outlet obstruction. BMJ Case Rep. 2017;2017:1-4. doi: 10.1136/bcr-2017-221928.

5. JainS.A.,Agarwal L.,KhyaliaA.etal.Pharmacobezoar-ararecasepresented as gastric outlet obstruction. J Surg Case Rep. 2018;2018(5):116. doi: 10.1093/jscr/rjy116.
6. Iwamuro M., Saito S., Yoshioka M. et al. A Case of a Magnesium Oxide Bezoar. Intern Med. 20181;57(21):3087-3091. doi: 10.2169/ internalmedicine.1124-18.

7. Von Düring S., Challet C., Christin L. Endoscopic removal of a gastric pharmacobezoar induced by clomipramine, lorazepam, and domperidone overdose: a case report. J Med Case Rep. 2019;13(1):45. doi: 10.1186/s13256-019-1984-0.

8. Baymakhanov A.N., Smagulov A.M., Kozhakhmetov T.K. et al. Gigantskiy trikhobezoar zheludka (kratniy obzor literatury i sobstvennoye klinicheskoye nablyudeniye) [Giant trichobesoar of the stomach (a brief review of the literature and our own clinical observation)]. Vestnik KazNMU. 2016;3(1):104-107. (In Russian).

9. Ezziti M., Haddad F., Tahiri M. et al. Gastric trichobezoar: about a case. Pan Afr Med J. 2017;26:74. doi: 10.11604/pamj.2017.26.74.11826.

10. Placone N., Mann S. A Trichobezoar of Gastric Proportions. Clin Gastroenterol Hepatol. 2020;18(2):e18. doi: 10.1016/j.cgh.2018.10.023.

11. Horesh N., Rosin D., DreznikY.etal. Asingletertiary center 10-year experience in the surgical management of gastrointestinal bezoars. J Laparoendosc Adv Surg Tech A. 2018;28(8):967-971. doi: 10.1089/lap.2017.0752.

12. Paparoupa M.,SchuppertF.Trichobezoar.Mayo Clin Proc.2016;91(2):2756. doi: 10.1016/j.mayocp.2015.11.004.

13. DaiQ.,JiangF.Ahugegastricbezoartreated bytraditional Chinesemedicine purgative: A case report. Medicine (Baltimore). 2018;97(50):e13712. doi: $10.1097 / M D .0000000000013712$.

14. Cerezo-RuizA., Domínguez-JiménezJ.L.,Uceda-Vaño A.Cellulase, CocaCola ${ }^{\circledR}$, pancreatin and ursodeoxycholic acid in the dissolution of gastric bezoars: why not all together?. Rev Esp Enferm Dig. 2018;110(7):472473. doi: $10.17235 /$ reed.2018.5617/2018.

15. Khan S., Jiang K., Zhu L.P. et al. Upper Gastrointestinal Manifestation of Bezoars and the Etiological Factors: A Literature Review. Gastroenterol Res Pract. 2019;2019:5698532. doi: 10.1155/2019/5698532.

16. Babayeva A.A. Rentgenologicheskaya diagnostika bezoarov v zheludochno-kishechnom trakte [Radiological diagnosis of bezoars in the gastrointestinal tract]. Vestnik novykh meditsinskikh tekhnologiy. 2017;11(3):129-134. (In Russian).

17. Barukhovich V.Ya., Pechenyuk M.A., Kokorkin A.D et al. Klinicheskiy sluchay trikhobezoara zheludka, oslozhnivshegosya pepticheskoy yazvoy bol'shoy krivizny. [A clinical case of trichobesoar of the stomach complicated by a peptic ulcer of great curvature]. KHírurgíya dityachogo víku. 2018;1:49-51. (In Russian).

18. Ebrahimian S., Ebrahimian S., Nadri S. Intraluminal bezoar caused obstruction and pancreatitis: A case report. Clin Case Rep. 2019;7(5):1040-1042. doi: 10.1002/ccr3.2145.

19. Iwamuro M., Tanaka S., Moritou Y. et al. Importance of second-look endoscopy on an empty stomach for finding gastric bezoars in patients with gastric ulcers. Acta Med Okayama. 2017;71(3):241-247. doi: 10.18926/AMO/55207.

20. Paschos K.A., Chatzigeorgiadis A. Pathophysiological and clinical aspects of the diagnosis and treatment of bezoars. Ann Gastroenterol. 2019;32(3):224-232. doi: 10.20524/aog.2019.0370.

21. Ogawa K., Kamimura K., Mizuno K.I. et al. The combination therapy of dissolution using carbonated liquid and endoscopic procedure for bezoars: pragmatical and clinical review. Gastroenterol Res Pract. 2016. doi: 10.1155/2016/7456242.

22. Iwamuro M., Yunoki N., Tomoda J. et al. Gastric bezoar treatment by endoscopic fragmentation in combination with Pepsi-Cola ${ }^{\oplus}$ administration. Am J Case Rep. 2015;16:445-8. doi: 10.12659/ AJCR.893786. 
23. Iwamuro M., Okada H., Matsueda K. et al. Review of the diagnosis and management of gastrointestinal bezoars. World J Gastrointest Endosc. 2015;7(4):336-45. doi: 10.4253/wjge.v7.i4.336.

24. Shidakov I.Kh., Kalniyazov B.M., Voytkovskiy A.Ye. Laparoskopicheskoye udaleniye trikhobeozoara zheludka [Laparoscopic removal of trichobeosoara of the stomach]. Rossiyskiy vestnik detskoy khirurgii, anesteziologii i reanimatologii. 2019;9(1):110-114. (In Russian).

The work was performed within the framework of the research work Department of Surgery 1 with a Course of Urology, National Pirogov Memorial Medical University, Vinnytsya, Ukraine "Development and improvement of the latest technologies in surgical treatment and prevention of postoperative complications in patients with organ diseases abdominal and thoracic cavity"(State registration number 0113U007692, scientific advisor - Grand PhD of Medical Sciences Volodymyr O. Shaprynskyi) and of the research work Department of Internal Medicine 3, National Pirogov Memorial Medical University, Vinnytsya, Ukraine "Pathogenetic parallels between neurohumoral, metabolic and structural-functional disorders and the nature of the course of various cardiovascular diseases and comorbid conditions, optimization of pharmacological correction" (State registration number 0114U007197, scientific advisor - Grand PhD of Medical Sciences Valerii P. Ivanov)

\section{ORCID and contributionship:}

Oleh O. Vorovskiy: 0000-0002-8933-3965 A,F

Yuliia Yu. Shushkovska: 000-0002-8006-5888 ${ }^{B, D}$

Oksana I. Afanasiuk: 0000-0001-7341-2899 C,E

\section{Conflict of interest:}

The Authors declare no conflict of interest.

\section{CORRESPONDING AUTHOR Oleh 0 . Vorovskiy \\ National Pirogov Memorial Medical University 10 Bortnyaka st., ap. 37, 21037 Vinnytsia, Ukraine tel: +380968493146 \\ e-mail: vorovskiysurgery@ukr.net}

Received: 27.05 .2020

Accepted: 18.11 .2020

A - Work concept and design, B - Data collection and analysis, C - Responsibility for statistical analysis, D-Writing the article, $\mathbf{E}$-Critical review, $\mathbf{F}$ - Final approval of the article 